\title{
DETECTANDO EARNINGS MANAGEMENT NO BRASIL: ESTIMANDO OS ACCRUALS DISCRICIONÁRIOS*
}

\author{
DETECTING EARNINGS MANAGEMENT IN BRAZIL: \\ ESTIMATING DISCRETIONARY ACCRUALS
}

\author{
ANTONIO LOPO MARTINEZ \\ Professor do Departamento de Contabilidade da Universidade Federal da Bahia \\ Doutor em Contabilidade e Controladoria pela Faculdade de Economia, Administraç̧ão e \\ Contabilidade da Universidade de São Paulo - SP. \\ Doutor em Finanças pela Escola de Addministração de Empresas de São Paulo da Fundação Getúlio Vargas - SP \\ E-mail: lopo@ufba.br
}

\section{RESUMO}

Este artigo analisa os modelos clássicos existentes na literatura acadêmica internacional para estimar os accruals discricionários, que são uma proxy empírica para detectar Earnings Manangement. Adicionalmente, evidencia que as Cias. Brasileiras "gerenciam" os seus resultados contábeis como resposta a estímulos do mercado de capitais. O primeiro passo é elucidar o significado de alguns conceitos relevantes tais como: accruals totais e accruals discricionários. Posteriormente, após uma análise crítica dos principais modelos de accruals agregados, implementar no contexto de empresas brasileiras, o modelo Kang e Silvaramakrishnan (1995), diagnosticado como o tecnicamente mais acurado para o Brasil. Para atestar a validade do modelo aplicado, investigamse circunstâncias em que o incentivo para gerenciamento de resultados é particularmente forte. Os resultados corroboram as hipóteses de gerenciamento de resultados para: a) Evitar reportar perdas; b) Sustentar o desempenho recente e c) Piorar o resultado presente em prol de resultados futuros (take a bath).

Palavras-chave: Gerenciamento dos resultados. Accruals. Accruals discricionários. Lucro líquido.

\section{ABSTRACT}

This paper analyzes classic models used in international academic literature to estimate discretionary accruals, which are an empirical proxy to detect earnings management. Additionally, it provides evidence that Brazilian public companies practice earnings management in response to capital market incentives. Initially, some important concepts are clarified, such as accruals and discretionary accruals. After a critical analysis of the main accruals model, the Kang \& Silvaramakrishnan model (1995) was implemented in the context of Brazilian companies, which is technically considered the most accurate model for Brazil. To check the robustness of the model, circumstances were investigated where there were strong incentives to practice earnings management. The results confirm the earnings management hypothesis. Evidences were documented that Brazilian public companies manage their earnings to: a) Avoid reporting losses; b) Sustain recent performance and c) Worsen the current net income in order to have better future results (take a bath).

Keywords: Earnings management. Accruals. Discretionary Accruals. Net income. 


\section{INTRODUC̣ÃO}

Um dos produtos mais importantes da contabilidade para os diversos usuários da informação financeira é o resultado (lucro/prejuízo). Muitas vezes é com base nesse número que se avalia o desempenho das empresas. Ocorre, entretanto, que parte desse resultado pode decorrer de ajustes contábeis de natureza discricionária, sem qualquer correlação com a realidade do negócio. Esses ajustes, no geral, seriam motivados por influências exógenas à empresa, que levam os seus executivos a "gerenciar" os resultados contábeis na direção em que se deseje.

Para este artigo, Earnings manangement é equivalente a "gerenciamento" dos resultados contábeis. As duas definições mais comuns na literatura para earnings management são de: i) SCHIPPER (1989): “... a purposeful intervention in the external financial reporting process, with the intent of obtain some private gain." e ii) Healy e Wahlen (1999): "earnings management occurs when managers use judgment in financial reporting to either mislead some stakeholders about the underlying economic performance of the company, or to influence contractual outcomes that depend on reported accounting numbers".

O tópico earnings management tem sido muito explorado na literatura internacional de contabilidade e finanças, entretanto a abordagem acadêmica se diferencia da imprensa especializada. Os profissionais e os reguladores, usualmente, revisam as práticas de earnings management na análise do caso a caso, baseados em situações especí- ficas de investigação a fraudes contábeis. Os acadêmicos, entretanto, possuem outra perspectiva de análise, eles buscam apresentar afirmações gerais, revisando grandes amostras de firmas. Os acadêmicos tendem a usar definições estatísticas, ainda que não sejam sempre acuradas em identificar o gerenciamento de resultados contábeis, porém têm sua validade para tentar explicar e prever motivações e conseqüências potenciais do gerenciamento de resultados contábeis.

Seguindo uma abordagem acadêmica, este artigo pretende discutir os modelos estatísticos de accruals agregados. Esses modelos assumem que as escolhas contábeis decorrentes de uma tentativa de gerenciamento de resultados, poderiam ser mensuradas por discretionary accruals (accruals discricionários). A identificação de modelos estatisticamente robustos é relevante à medida que propicia ao pesquisador um ferramental mais confiável para estudo e análise.

Uma conseqüência do gerenciamento de resultados é o comprometimento da qualidade da informação contábil, esse fenômeno pode criar sérias ineficiências alocativas entre empresas, assim como provocar distribuições de riquezas injustificáveis, com danosas conseqüências para o incipiente mercado de capitais brasileiro. Diante desse potencial problema, urge, também, constatar se ocorre gerenciamento de resultados contábeis no Brasil, bem como quais seriam algumas de suas motivações.

\section{ACCRUALS DISCRICIONÁRIOS}

A diferença entre o lucro líquido e o fluxo de caixa operacional líquido é conhecida como accruals (acumulações). Portanto, accruals seriam todas aquelas contas de resultado que entraram no cômputo do lucro, mas que não implicam em necessária movimentação de disponibilidades.

Nada de errado existe no registro de accruals; na verdade, o intuito é mensurar o lucro no seu sentido econômico, aquele que representa acréscimo efetivo na riqueza patrimonial da unidade econômica, independente da movimentação financeira. O problema está no fato de o gestor discricionariamente aumentar ou diminuir esses accruals com o objetivo de influenciar o lucro.

Considerando que eventualmente o "gestor" possa tomar a decisão de aumentar ou diminuir os accruals por motivos alheios à realidade do negócio, cria-se a necessidade didática de subdiví-los em: accruals discricionários (discretionary accruals) e accruals não discricionários (non discretionary accruals). Esses últimos seriam os exigidos de acordo com a realidade do negócio, os primeiros seriam artificiais e teriam como único propósito "gerenciar" o resultado contábil (earnings management).

Os accruals discricionários são uma proxy do gerenciamento de resultados contábeis. O desafio de trabalhos na área de gerenciamento dos resultados contábeis é estimar o valor dos accruals discricionários (AD). Os AD podem ser positivos ou negativos, representando, respectivamente, que a empresa está gerenciando seus resultados para melhorá-los ou piorá-los.

Tendo em vista que as contas de resultado possuem contrapartidas no balanço patrimonial, é possível estimar o valor dos accruals totais, a partir das variações dos itens específicos no balanço patrimonial. As contas de resultados nem sempre discriminam exatamente o montante de accruals. Por exemplo, numa receita de vendas, parte pode representar entrada de caixa, outra pode ser tão somente aumento de contas a receber.

A diferença entre a contabilidade pelo regime de caixa e a contabilidade pelo regime de competência reside no aspecto temporal de reconhecimento de receitas e despesas. A longo prazo, os dois sistemas proporcionam o mesmo resultado. Entretanto, no curto prazo, o processo de reconhecimento de receitas e despesas cria diferenças. Perante esse fato, o "gerenciamento" de resultados contábeis nada mais é que outra maneira de tratar a diferença existente entre os dois sistemas. A seguir, é esboçado um diagrama sobre os conceitos discutidos: 


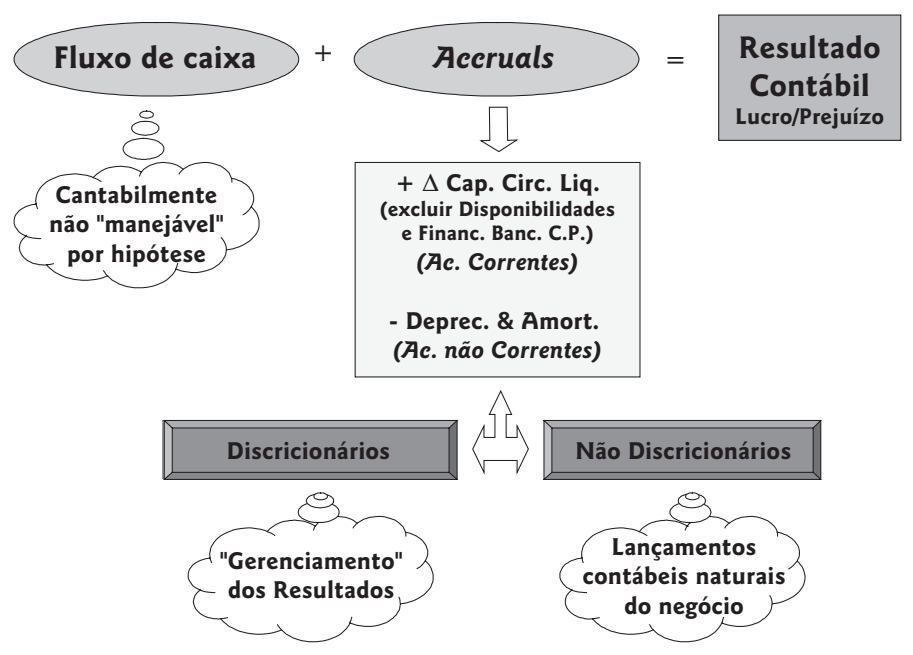

Figura 1 Diagrama ilustrativo dos conceitos

Quando se analisa em termos dos accruals discricionários ( $A D)$, é possível definir-se, também, um padrão de comportamento, de acordo com a sua variabilidade. Registre-se, entretanto, que o valor a ser assumido pelos AD tem sempre um limite que dependerá de cada empresa em particular. Ou seja, por mais que se possa "manejar" o resultado num sentido desejado sempre se encontrará uma restrição nas próprias contas contábeis. Por exemplo, não se poderá provisionar uma depreciação em valor superior aos ativos. Considerando, por hipótese, que exista um montante máximo de AD positivos e de AD negativos. Pode-se graficamente visualizar os diferentes tipos de gerenciamento de resultados no Quadro 10

\section{REVISÃO DA LITERATURA: MODELOS DE ACCRUALS AGREGADOS}

Para qualquer teste na área de "gerenciamento" dos resultados contábeis, é muito importante mensurar a discricionariedade da gestão sobre os lançamentos contábeis dos accruals. O desafio de qualquer modelo é encontrar a melhor estimativa de qual seria o valor dos accruals discricionários (AD). Os modelos oscilam de muito simples a mais sofisticados, visando sempre separar o com- ponente discricionário do não-discricionário no resultado contábil.

O primeiro esforço em produzir um modelo para estimar o componente discricionário é atribuído a Healy (1985), no qual foram usados os valores dos accruals totais como sucedâneos (proxies) da discricionariedade da gestão sobre os lucros.

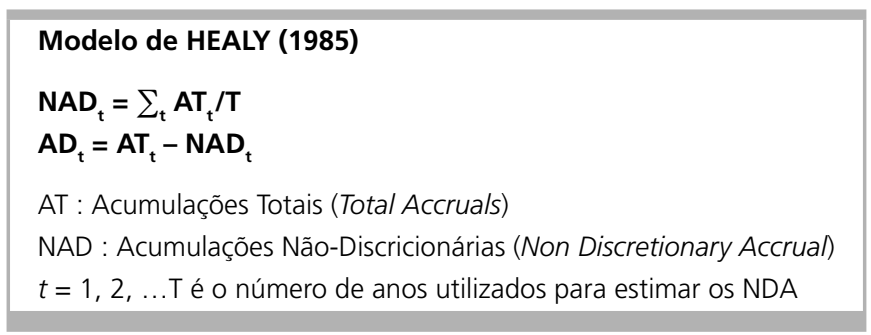

Apenas com o modelo de JONEs (1991), foi introduzida a abordagem de regressões para controlar os accruals não discricionárias (NAD) e, a partir daí, estimar indiretamente o valor dos accruals discricionários (AD).

O modelo de Jones supõe que os accruals não discricionários (NAD) dependem da variação nos níveis de receitas e dos valores dos Ativos Imobilizados. A idéia é de que os volumes dos accruals correntes necessários dependem da receita e os accruals não correntes (depreciação) dependem do montante do ativo imobilizado. Portanto, uma vez que o modelo seja implementado, executado uma regressão múltipla (por séries temporais ou entrecruzadas - crosssectional), o pesquisador utilizará os coeficientes estimados para calcular os accruals não-discricionários (NAD) e, a partir daí, a diferença em relação aos accruals totais se computará os accruals discricionários (AD). A questãochave é perguntar: Será que esse modelo efetivamente funciona bem? 


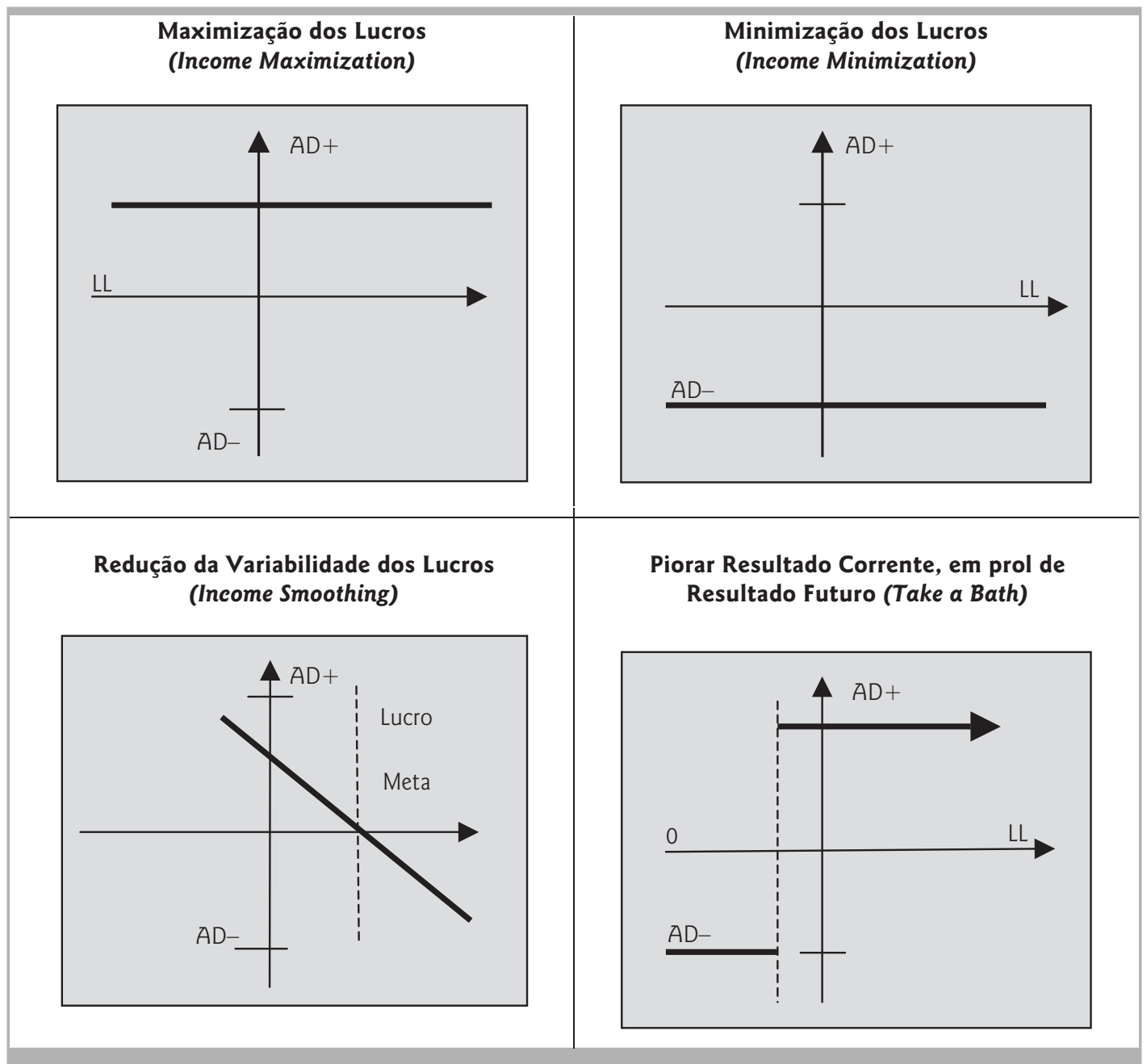

Quadro 1 || Padrões de "Gerenciamento" de Resultados Contábeis a partir dos Accruals Discricionários (AD)

Notas ao Quadro 1:

Padrões de "Gerenciamento" dos Resultados Contábeis a partir dos accruals discricionários (AD). Entende-se por AD todos os lançamentos contábeis associados ao princípio da competência, que não envolvem caixa, e em que a avaliação discricionária do gestor é crucial para o reconhecimento de uma receita/despesa. No eixo horizontal, está registrado o Lucro Líquido (LL), oscilando de valores negativos a valores positivos. No eixo vertical, estão os $A D$, oscilando de um limite negativo máximo, até um limite positivo máximo. Os $A D+$ aumentam o lucro e os $A D$ - diminuem o lucro.

Na maximização dos lucros, observa-se que, independente do montante de lucro, os AD+ estão no seu valor máximo. Na minimização dos lucros, constata-se que os $A D$ - estão no seu valor máximo. Na redução da variabilidade dos resultados, quando o LL for menor que o Lucro Meta se estará gerenciando para melhorar os resultados $(A D+)$, quando o $\amalg$ for maior que o lucro meta se estará gerenciando para piorar os resultados (AD-). Finalmente, no gerenciamento para piorar resultados constata-se que, quando a empresa não atinge um determinado patamar de resultado (prejuízo pequeno), essa escolhe por gerenciar o resultado de modo a piorá-lo ainda mais.

Muitas das críticas ao modelo Jones estão baseadas no risco de erro de classificação. Na verdade, para qualquer modelo usado para estimar os accruals discricionários existe sempre o risco de esse problema estar presente.

$$
\begin{aligned}
& \text { Modelo de JONES (1991) } \\
& \mathbf{A T}_{\mathrm{it}}=\alpha\left(1 / \mathbf{A}_{\mathrm{t}-1}\right)+\beta\left(\Delta \text { Receitas }_{\mathrm{it}}\right)+\gamma\left(\text { At.Imob }_{\mathrm{it}}\right)+\varepsilon_{\mathrm{it}} \\
& \mathbf{N A D}_{\mathrm{it}}=\alpha\left(1 / \mathbf{A}_{\mathrm{t}-1}\right)+\beta\left(\Delta \text { Receitas }_{\mathrm{it}}\right)+\gamma\left(\text { At.Imob }_{\mathrm{it}}\right) \\
& \mathbf{A D}_{\mathrm{it}}=\mathbf{A T}_{\mathrm{it}}-\mathbf{N A D}_{\mathrm{it}}
\end{aligned}
$$

$\Delta$ Receitas $_{\text {it }}=$ receitas oper. Líquidas no ano $t$ menos receitas no ano $t-1$ escalado pelos Ativos de $t-1$; At.Imob : Ativo Imobilizado no t;

$\mathrm{A}_{\mathrm{t}-1}$ : Ativos totais em $t$ a $t-1$;

$\alpha, \beta, \gamma=$ coeficientes estimados por regressão. 
Um erro na classificação entre accruals discricionários (AD) e accruals não discricionários (NAD) reduz a força do teste e, no melhor cenário, reduz o poder de todo o procedimento metodológico adotado, mas, na pior situação, pode até levar o pesquisador a concluir que existe "gerenciamento" dos resultados contábeis (earnings management), quando, na verdade, nada está ocorrendo.
Dechow, Sloan e Sweeney (1995) comparam os cinco modelos usualmente utilizados para estimar AD e concluem que o modelo de Jones (na sua versão modificada) oferece os melhores resultados. Entretanto, no mesmo trabalho os autores reconhecem que nenhum dos modelos oferece um método forte de estimativa.

\section{Modelo modificado de JONES (1995)}

$\mathbf{N A D}_{i \mathrm{it}}=\alpha\left(\mathbf{1}_{\mathrm{A}} \mathbf{A}_{\mathrm{t}-1}\right)+\beta\left(\Delta\right.$ Receitas $_{\mathrm{it}}-\Delta \mathbf{C}$ Receb $\left._{\mathrm{it}}\right)+\gamma\left(\right.$ At.Imob $\left._{\mathrm{it}}\right)$

$\Delta C \cdot$ Receb $_{\text {it }}=$ contas a receber líquidas no ano $t$ menos o valor das contas a receber líquidas no ano $t-1$ escaladas pelos ativos totais em $t-1$

Embora a maioria da literatura utilize o modelo de JONES para estimar os AD, acredita-se que provoca sérios erros de classificação. Entre os problemas percebidos, destacam-se:

a) Erros nas variáveis: Alguns itens que podem ser manipulados não são considerados no modelo de JONES. Por exemplo, o controle efetuado com a variável receitas ignora que as próprias receitas podem estar sendo manipuladas;

b) Variáveis omitidas: $O$ modelo de JONES não controla variações nas despesas;

c) Simultaneidade: Uma vez que, no processo de estimativa, tanto as variáveis explicativas como as variáveis explicadas são conjuntamente determinadas, isso provoca problemas de autocorrelação viesando os resultados da regressão.

O problema de simultaneidade aparece em função de que tanto os regressores como os regressandos são, conjuntamente, determinados através das restrições impostas pelos princípios contábeis e pelo princípio do débito e crédito. Note-se que essas restrições são independentes tanto do "gerenciamento" dos resultados contábeis como dos problemas associados a variáveis omitidas.

Em resposta a todos esses problemas, a melhor alternativa é o modelo de KanG-SivaramaKRISHNAN (1995) [KS]. Até onde se tem conhecimento, na literatura, nenhum outro modelo revisa cada um dos problemas anteriormente identificados. Para mitigar os problemas de variáveis omitidas, o modelo KS inclui as despesas operacionais na regressão, bem como trata das contas a receber para lidar com eventuais problemas associados à manipulação nas receitas. $E$, finalmente, para corrigir o problema de simultaneidade, é empregada a metodologia de variáveis instrumentais.

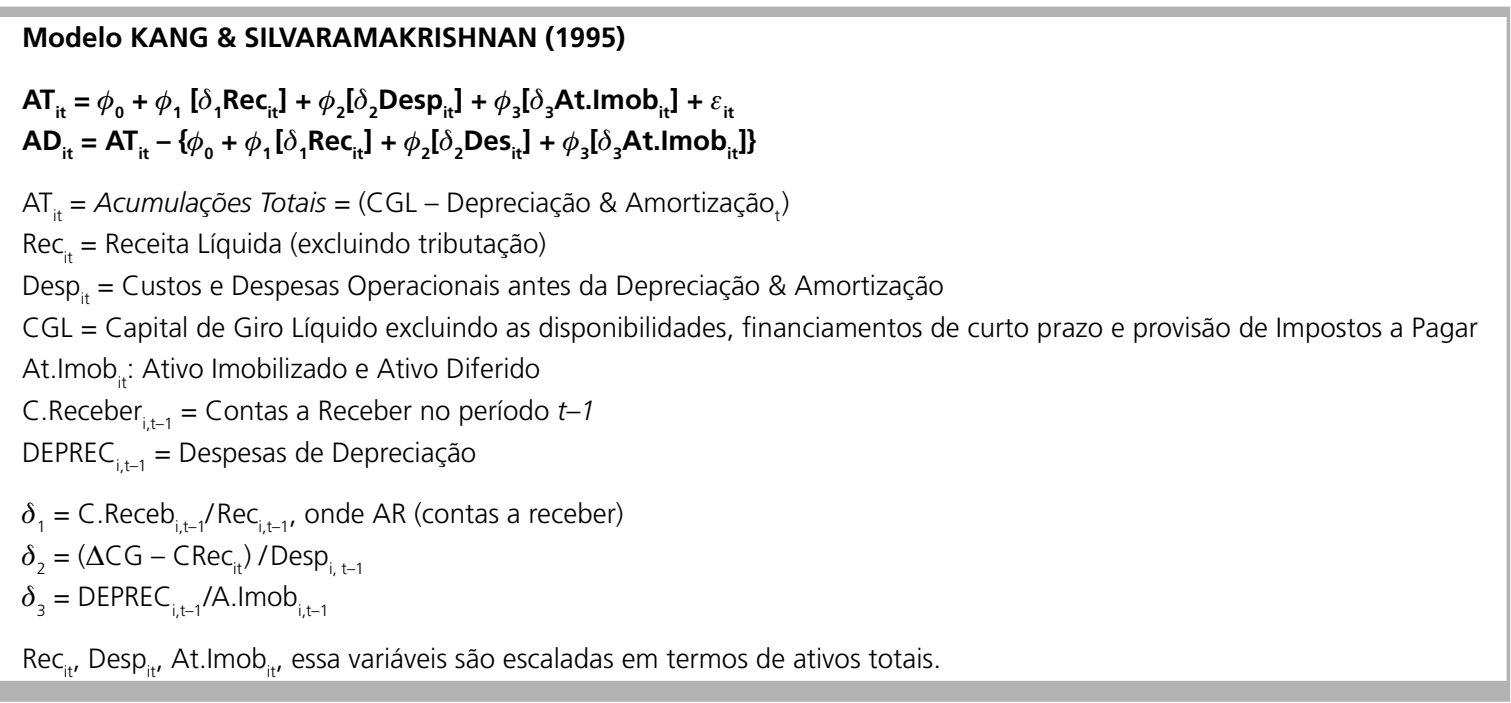

O modelo KS opera diretamente com as contas do balanço patrimonial em determinado exercício contábil, evi- tando-se, desse modo, o indesejável problema de comparar valores em moeda de diferentes períodos (o que não é 
o caso do modelo de JonEs, pois esse utiliza a variação das contas de resultados). Esse detalhe metodológico ganha relevância no Brasil, quando se considera o aspecto inflacionário, que comprometeria a comparabilidade entre dois exercícios.

À medida que o método contempla, simultaneamente, aspectos da teoria contábil e da boa técnica econométrica, espera-se que os resultados sejam mais robustos. Para reforçar esse argumento, cabe registrar os comentários de ThOMAs e Zhang (2000) que revisou todas as técnicas de estimativas dos accruals discricionários (discretionary accruals): "We have investigated the accuracy of six different accrual predictions models, and offer the following findings... Only the Kang-Sivaramakrishnan (1995) model performs moderately well." Logo, não existe modelo perfeito, mas o modelo KS é, dentro do estado da arte atual, aquele que proporciona os melhores resultados. Isso posto, no restante do artigo, estimam-se os accruals discricionários das empresas brasileiras, utilizando o modelo KS.

\section{ESTIMANDO ACCRUALS DISCRICIONÁRIOS COM O MODELO KS PARA CIAS. BRASILEIRAS}

\subsection{Variáveis do modelo KS ajustadas à realidade brasileira}

$\mathrm{O}$ modelo KS opera diretamente com as contas do balanço patrimonial, procurando explicar a dimensão dos Accruals Totais. Cabe discutir o tratamento específico que se sugere que seja realizado em cada variável de modo a refletir mais corretamente a realidade brasileira.

A variável AT (Accruals Totais) constitui a variação do capital de giro líquido excluído das disponibilidades e financiamentos de curto prazo, que será subtraído do total da depreciação e amortização, sendo esse saldo final medido em termos de porcentagem dos ativos totais. Acrescente-se que, caso existam provisões (ou créditos) tributárias, esses, também, devem ser excluídos no cômputo das AT.

Para efeito do calculo dos accruals totais de natureza não corrente, levou-se em consideração apenas a depreciação e a amortização. Nesse sentido, fica neutralizado o eventual gerenciamento de resultados mediante as ativações cambiais que ocorreram no período de estudo. 0 objetivo foi analisar, fundamentalmente, Current Accruals e Depreciações \& Amortizações.

A Rec representa a Receita Líquida excluída dos impostos incidentes sobre o faturamento, e a Desp representa o total de despesas operacionais (CMV, CPV, Desp. de Vendas e Administrativas), antes da depreciaçãoEamortização e juros, variável medida em termos de porcentagem dos ativos totais.

No tocante à variável $\mathbf{A}$.Imob, o modelo original sugere a utilização das contas Propriedades, Plantas e Equipamentos, que seria equivalente ao somatório do Ativo Imobilizado e Ativo Diferido, estimado em termos brutos. Entretanto, nesse ponto, encontra-se grave restrição à aplicabilidade plena do modelo no Brasil. Lamentavelmente, verificou-se que muitas empresas não segregam em seus balanços, com detalhes, as contas do ativo diferido e ativos imobilizados, bem como, em vários casos, os valores nem sempre são utilizados em termos brutos. Diante dessa restrição, foi utilizado o valor do Ativo Permanente como todo, como proxy para o PPE. Em termos práticos, se houve conseqüência desse procedimento, foi a redução da importância da Depreciação \& Amortização.
Os parâmetros $\delta_{1}, \delta_{2}$ e $\delta_{3}$ podem ser interpretados como os indicadores de rotatividade que procuram acomodar fatores específicos da firma e compensam o fato de a equação do modelo KS estar sendo estimada em amostra conjunta de várias empresas entrecruzadas (cross-sectional). $\mathrm{O}$ indicador $\delta_{1},\left[\delta_{1}=\mathrm{CR}_{\mathrm{i}, \mathrm{t}-1} / \operatorname{Rec}_{\mathrm{i}, \mathrm{t}-1}\right]$, representa a razão entre contas a receber e receitas do ano anterior, que será multiplicada pelas vendas do período corrente $\left[\delta_{1} \times \operatorname{Rec}_{i t}\right]$.

De modo similar, o indicador $\delta_{2},\left[\delta_{2}=\left(\mathrm{CGL}_{\mathrm{it}-1}-\mathrm{CR}_{\mathrm{it}-1}\right) /\right.$ Desp $\left._{\mathrm{i}, \mathrm{t}-1}\right]$, representa a razão entre o capital de giro líquido (excluído das disponibilidades, financiamento de curto prazo e contas a receber) e as despesas operacionais do período anterior, que será multiplicada pelas despesas operacionais do período corrente $\left[\delta_{2} x\right.$ Desp $\left.p_{i t}\right]$. Por sua vez, o $\delta_{3},\left[\delta_{3}=\operatorname{DEPR}_{\mathrm{i}, \mathrm{t}-1} /\right.$ A.Per $\left._{\mathrm{i}, \mathrm{t}-1}\right]$, constitui a razão entre as despesas de depreciação e os ativos permanentes do período anterior, que será multiplicada pelo ativo permanente do período corrente $\left[\delta_{3} \times A \cdot \operatorname{Per}_{i t}\right]$.

\subsection{Modelos empíricos aplicados}

A estimativa dos accruals discricionários envolve, inicialmente, que seja rodada a regressão para estimar os coeficientes que precedem às variáveis utilizadas. Esses coeficientes devem representar a melhor maneira de descrever o valor dos accruals totais para o contexto das empresas. Calculados os coeficientes, o passo seguinte é verificar o erro, a diferença entre o valor dos accruals totais e o valor estimado a partir dos coeficientes.

Deve-se utilizar o método econométrico mais apropriado, pois é do valor dos erros da regressão que é extraído aquele componente que será as AD para cada firma. Utilizando procedimentos variados, procurou-se estimar o erro da melhor maneira possível. Desse modo, foram implementados quatro modelos que procuravam cobrir eventuais problemas que poderiam existir e permitir a escolha do modelo mais robusto para as análises posteriores.

\section{Modelo 1.1 Modelo KS com regressão pelo mé- todo dos mínimos quadrados}

Nesse modelo, foi efetuada regressão múltipla pelo método dos mínimos quadrados simples. Através da regres- 
são, procurou-se minimizar os erros em relação às variáveis explicativas. Teoricamente, sabe-se que esse modelo apresenta sérias restrições técnicas, entretanto executa-se para se ter idéia comparativa com os modelos tecnicamente superiores.

\section{Modelo 1.2 Modelo KS incluindo variáveis biná- rias (dummies) para os anos}

Incorporam-se ao Modelo $\mathbf{1 . 1}$ variáveis binárias (dummy) para controle de anos. Na regressão, é excluída a variável binária para um dos anos, tal como preceitua a técnica econométrica. O uso de variáveis binárias para anos verifica se, nos erros, teriam sido incluídas particularidades de cada ano. Talvez, em alguns anos, fosse possível encontrar características específicas que explicassem o comportamento da variável dependente.

\section{Modelo 1.3 Modelo KS incluindo variáveis biná- rias (dummies) para setores}

Incorporam-se ao Modelo 1.1 variáveis binárias para controle de setores econômicos. Nosso grupo de análise está classificado em 19 setores econômicos. Para efeito da regressão, foram feitas as análises com 18 variáveis binárias de setor. O propósito da variável binária para o setor é verificar se existe alguma particularidade por setor que se manifeste nos erros.

\section{Modelo 1.4 Modelo KS, usando variáveis instru- mentais}

O modelo que utiliza variáveis instrumentais é superior pelo fato de analisar as características dos erros de modo mais preciso. Sabe-se que deve existir correlação entre os erros e as variáveis independentes; assim como há entre os accruals discricionários (AD) e os accruals não discricionárias (NAD). Se aumentar uma das variáveis, digam-se os $A D$, como conseqüência a outra terá que ser reduzida, e os NAD cairão. Recorde-se que os Accruals Totais = AD + NAD. Diante desses problemas de correlação entre as variáveis, um modo de corrigir a falha é a utilização da técnica de variáveis instrumentais.

Com as variáveis instrumentais realiza-se a regressão em dois estágios, em que se procura neutralizar o viés que seria provocado por se executar a regressão sem os devidos cuidados. Para a operacionalização das variáveis instrumentais é crucial a identificação dos instrumentos, que seriam variáveis que se correlacionam com as variáveis independentes, mas que não devem correlacionar-se com os erros. Neste trabalho, como instrumentos foram escoIhidos os indicadores de rotatividade $\left(\delta_{1}, \delta_{2}, \delta_{3}\right)$ defasados de um período. A escolha tem respaldo técnico nas observações de Kennedy (1998:142): "It may be possible to use as an instrument the lagged value of independent variable in question; it is usually correlated with the original independent variable, and, although it is correlated with the distur- bance vector, because it is lagged it is not contemporaneously correlated with the disturbance".

\subsection{Base de dados}

Os dados para a analise foram coletados do sistema Economática. O modelo mais restritivo no tocante às observações foi o Modelo 1.4, que, além das variáveis utilizadas nos modelos anteriores, demanda a disponibilidade de informações relativas aos instrumentos, sendo necessário coletar dados retrocedendo três anos antes do primeiro ano de estudo.

Para a verificação da consistência do modelo, coletaramse dados no economática a partir de 1995 até 2004. No total para 282 firmas foi possível formar a base de dados relativa ao período de 1998 a 2004. Acrescente-se, por pertinente, que a referida amostra de empresas, inclui firmas de diversos setores econômicos, exceto instituições de natureza financeira. A amostra na sua diversidade representa adequadamente o comportamento médio das empresas brasileiras abertas. Na Tabela $1 \bullet$ são apresentados os resultados dos diversos modelos de que é possível serem extraídas conclusões interessantes. O Modelo $\mathbf{1 . 1}$ apresentou estatísticas satisfatórias tanto no teste t e teste F.. Entretanto, sabe-se que o modelo não expressa a realidade, dada a existência de correlação entre as variáveis e os erros.

O Modelo 1.2 demonstrou não existir grande diferença entre os anos para efeito de cálculo dos accruals discricionários (discretionary accruals), uma vez que os coeficientes da regressão foram muito similares. Embora não relatado na tabela, apenas a variável binária do ano de 2001 apresentou uma relativa significância, porém ainda baixa para os padrões estatísticos usuais.

Quanto ao Modelo $\mathbf{1 . 3}$ percebe-se que as variáveis ligadas aos setores foram anuladas na regressão. E o coeficiente $\mathrm{R}^{2}$ ajustado aumentou, indicando a existência de eventual problema de multicoliniaridade devido à introdução de número muito elevado de variáveis binárias.

Finalmente, o Modelo 1.4, tecnicamente o mais completo, evidenciou resultados satisfatórios, com significante estatística F. O ponto crítico da análise foi o resultado da variável ligada aos Ativos Permanentes. Para essa variável, a estatística t demonstrou não ser significativamente diferente de zero. Apesar do resultado modesto para esse item, decidiu-se conservar esse parâmetro, embora reconhecendo o risco de novos problemas de mensuração estarem sendo incorporados.

Diante dos diversos modelos e entendendo que as variáveis instrumentais são a resposta técnica mais compatível com o problema, estimaram-se os accruals discricionários (discretionary accrual) usando o Modelo 1.4. O cálculo dos erros mostrou distribuição entre as empresas que possuíam AD positivos (aumentando os resultados) em determinados anos, e outros grupos de empresas que possuíam AD negativos (diminuindo seus resultados). 
Tabela 1 Estimativa dos Accruals Discricionários (Discretionary Accruals) - Modelo KS Modificado - Cias. Brasileiras Abertas (1998-2004)

\begin{tabular}{|c|c|c|c|c|c|c|c|c|}
\hline Variáveis & $A T / A_{t}$ & S.P. & $A T / A_{t}$ & S.P. & $A T / A_{t}$ & S.P. & $A T / A_{t}$ & S.P. \\
\hline$\delta_{1}$ *rec & $\begin{array}{r}0,063 \\
(1.429)\end{array}$ & + & $\begin{array}{r}0,06 \\
(1.35)\end{array}$ & + & $\begin{array}{l}0,067 \\
(1.47)\end{array}$ & + & $\begin{array}{r}-0,092 \\
(-0.421)\end{array}$ & + \\
\hline$\delta_{2}{ }^{*}$ desp & $\begin{array}{c}0,049 \\
(13,49)^{\star \star *}\end{array}$ & + & $\begin{array}{c}0,049 \\
(13.51)^{\star * *}\end{array}$ & + & $\begin{array}{c}0,048 \\
(12.94)^{\star * *}\end{array}$ & + & $\begin{array}{c}0,58 \\
(12,02)^{\star * *}\end{array}$ & + \\
\hline$\delta_{3}{ }^{*}$ aper & $\begin{array}{l}-0,294 \\
(-2.82)^{\star * *}\end{array}$ & $+/-$ & $\begin{array}{l}-0,294 \\
(-2.83)^{\star * *}\end{array}$ & $+/-$ & $\begin{array}{l}-0,242 \\
(-2.24) \\
\end{array}$ & $+/-$ & $\begin{array}{r}-0,683 \\
(-0.355) \\
\end{array}$ & $+/-$ \\
\hline a99-a04 & & & $\begin{array}{l}0 \\
0 \\
\end{array}$ & $?$ & & & & \\
\hline s02-S19 & & & & & $\begin{array}{l}0 \\
0 \\
\end{array}$ & $?$ & & \\
\hline Constante & $\begin{array}{c}-0,048 \\
(-3.289)^{\star * *}\end{array}$ & $?$ & $\begin{array}{r}-0,039 \\
(-1,165) \\
\end{array}$ & $?$ & $\begin{array}{l}-0,032 \\
(-0,24) \\
\end{array}$ & $?$ & $\begin{array}{r}-0,003 \\
(-0,026) \\
\end{array}$ & $?$ \\
\hline $\begin{array}{l}\text { Observ. } \\
\mathrm{R}^{2} \text { ajust. }\end{array}$ & $\begin{array}{r}1970 \\
0,088 \\
\end{array}$ & & $\begin{array}{r}1970 \\
0,094 \\
\end{array}$ & & $\begin{array}{r}1970 \\
0,09 \\
\end{array}$ & & $\begin{array}{c}1732 \\
\text { N.A. } \\
\end{array}$ & \\
\hline F Teste & $64,35 * * *$ & & $22.56 * * *$ & & $10.31 * * *$ & & $61.83^{* * *}$ & \\
\hline
\end{tabular}

Notas: Tabela 1

Modelo de Kang \& Silvaramakrishnam (1995)

$\mathrm{AT}_{\mathrm{it}}=\phi_{0}+\phi_{1}\left[\delta_{1} \operatorname{Rec}_{\mathrm{it}}\right]+\phi_{2}\left[\delta_{2} \operatorname{Desp}_{\mathrm{it}}\right]+\phi_{3}\left[\delta_{3} A\right.$ Perm $\left.\mathrm{it}\right]+\varepsilon_{\mathrm{it}}$

$A D_{i t}=A T_{i t}-\left\{\phi_{0}+\phi_{1}\left[\delta_{1} \operatorname{Rec}_{i t}\right]+\phi_{2}\left[\delta_{2} \operatorname{Desp}_{i t}\right]+\phi_{3}\left[\delta_{3} A P e r m i t\right]\right\}$

AT $=$ Accruals Totais $=\Delta$ Capital de Giro Líquido - Deprec $\&$ Amort

Ind $1=\delta_{1}=\mathrm{CR}_{\mathrm{i}, \mathrm{t}-\mathrm{l}} / \operatorname{Rec}_{\mathrm{i}, \mathrm{t}-\mathrm{l}}$, onde CR (Contas a Receber)

Ind $2=\delta_{2}=\left(\mathrm{CGL}_{\mathrm{it}-1}-\mathrm{CR}_{\mathrm{it}-1}\right) / \operatorname{Desp}_{\mathrm{i}, \mathrm{t}-1}$

Ind3 $=\delta_{3}=$ DEPR $_{\mathrm{i}, \mathrm{t}-1} /$ A.Perm $\mathrm{i}_{\mathrm{t}-\mathrm{1}}$

S.P. $=$ Sinal Previsto

Modelo 1.1 Modelo ks com Regressão Mét. Mínimos Quadrados Nesse modelo, foi efetuada uma regressão múltipla pelo método OLS

Modelo 1.2 Modelo KS incluindo variáveis binárias para anos

Incorporam-se ao Modelo 1.1, variáveis binárias para controle de anos. Na regressão, é excluída a variável binária do ano de 1998.

Modelo 1.3 Modelo KS incluindo variáveis binárias para setores

Incorporam-se ao Modelo 1.1, variáveis binárias para controle de setores econômicos. Nosso grupo de análise está classificado em 19 setores econômicos. Para efeito da regressão foram feitas as análises com 18 variáveis binárias de setor.

Modelo 1.4 Modelo KS, usando Variáveis Instrumentais. Como instrumentos usaram-se as variáveis Ind1, Ind2 e Ind3 defasadas de um ano.

\section{AVALIANDO O MODELO EM SITUACCÕES DE INCENTIVO A EARNING MANAGEMENT}

Depois de calculados os accruals discricionários para cada empresa-ano do grupo de controle, apresentam-se, a seguir, alguns testes utilizados para verificar a coerência e validade das estimativas. Na Tabela $2 \bullet$ são documentadas algumas observações realizadas, que atestam a coerência dos resultados apresentados.

\section{1 "Gerenciamento" de resultados para evitar reportar perdas}

Para Burgstahler e Dichev (1997), as firmas evitam anunciar resultados com pequenos prejuízos, pois esses enviam um sinal de desempenho pobre; o preferível é realizar um pequeno lucro. Nesse sentido, espera-se que as empresas que irão reportar um pequeno prejuízo gerenciem o seu resultado aumentando-o e passando a reportar pequenos lucros.

Para testar essa hipótese, verifica-se qual o comportamento dos accruals discricionários ao redor do resultado zero. Na amostra de firmas, foram classificadas as empresas-ano no grupo de controle de acordo com o lucro líquido escalado pelos ativos, enquadrando-as em quatro subgrupos entre $-5,0 \%$ até $5,0 \%$, conforme se verifica no Painel A da Tabelas 2. Os resultados indicaram que para as empresas que estão na faixa de $0 \%$ a $2,5 \%$ as $A D$ são positiva e significativamente diferentes de zero, sendo o grupo em que mais predominam os valores positivos $64,01 \%$. Os dados levam à conclusão de que, entre as firmas que estão 
Tabela 2 Detectando "gerenciamento" dos resultados contábeis no grupo de controle - Cias. Brasileiras Abertas (1998-2004)

Painel A: Cias. Brasileiras com lucros líquidos próximo de zero, distribuídas em termos de LLAT ${ }_{t}$ (lucros líquidos escalados por ativos totais) e Accruals Discricionários

\begin{tabular}{|c|c|c|c|c|}
\hline & $-5 \%<=$ LL/At $<-2,5 \%$ & $-2,5 \%<=$ LL/At $<0 \%$ & $0 \%<=$ LL/At $<2,5 \%$ & $2,5 \%<=$ LL/At $<5,0 \%$ \\
\hline A.D. Positiva & $51,64 \%$ & $53,40 \%$ & $64,01 \%$ & $60,61 \%$ \\
\hline A.D. Negativa & $48,36 \%$ & $46,60 \%$ & $35,99 \%$ & $39,39 \%$ \\
\hline A.D. Média & 0,01694 & 0,01437 & 0,02538 & 0,02169 \\
\hline Estatística T & 1,895 & 1,825 & 4,999 & 3,813 \\
\hline
\end{tabular}

Painel B: Cias Brasileiras com alto MVIBV ratio, distribuídas em termos de $\delta L_{L} A_{t}$ (variação do lucro líquido) e Accruals Discricionários

\begin{tabular}{l|c|c|} 
& $-\mathbf{1 , 0} \%<\delta \mathbf{L L} / \mathbf{A}_{\mathbf{t}}<\mathbf{0} \%$ & $\mathbf{0 , 0} \% \mathbf{=} \delta \mathbf{L L} / \mathbf{A}_{\mathbf{t}}<\mathbf{1 , 0} \%$ \\
A.D. Positiva & $53,07 \%$ & $61,90 \%$ \\
\hline A.D. Negativa & $46,93 \%$ & $38,10 \%$ \\
\hline & & \\
\hline A.D. Média & $-0,0055$ & $\mathbf{0 , 0 2 2 4}$ \\
\hline Estatística T & $-0,610$ & $\mathbf{3 , 1 9 2}$
\end{tabular}

Painel C: Accruals discricionários (AD) organizada em quintiles decrescentes de empresas aumentando o resultado para aquelas reduzindo o resultado.

\begin{tabular}{ll|c|c|c} 
Quintiles & & $\mathbf{A D}_{\mathbf{t}}$ & $\mathbf{A T}_{\mathbf{t}} / \mathbf{A}_{\mathbf{t}}$ & $\mathbf{L L}_{\mathbf{t}}$ \\
\hline Aumentando Lucro & 1 & 0,1873 & 0,1242 & $1,28 \%$ \\
\hline & 2 & 0,0607 & 0,0085 & $2,05 \%$ ** \\
\hline & 3 & 0,0135 & $-0,0356$ & $0,49 \%$ \\
\hline Diminuindo Lucro & 5 & $-0,1447$ & $-0,2026$ & $-11,06 \%$ **
\end{tabular}

Painel D: Matriz de Transição para Accruals discricionários

\begin{tabular}{c|c|c|c|c|c|c|} 
Ano t & Ano t+1 & $\mathbf{1}$ & $\mathbf{2}$ & $\mathbf{3}$ & $\mathbf{4}$ & $\mathbf{5}$ \\
\hline & $\mathbf{1}$ & $25,00 \%$ & $18,67 \%$ & $14,67 \%$ & $17,67 \%$ & $24,00 \%$ \\
\hline & $\mathbf{2}$ & $19,33 \%$ & $24,33 \%$ & $20,33 \%$ & $18,00 \%$ & $18,00 \%$ \\
\hline & $\mathbf{3}$ & $15,00 \%$ & $22,00 \%$ & $28,00 \%$ & $22,67 \%$ & $12,33 \%$ \\
\hline & $\mathbf{4}$ & $17,67 \%$ & $16,00 \%$ & $23,33 \%$ & $25,33 \%$ & $17,67 \%$ \\
\hline & $\mathbf{5}$ & $23,00 \%$ & $19,00 \%$ & $13,67 \%$ & $16,33 \%$ & $28,00 \%$ \\
\hline
\end{tabular}

\section{Notas: Tabela 2:}

Painel C: O grupo de controle foi dividido em cinco partes (quintis) classificadas em ordem decrescente dos Accruals discricionários

Para cada grupo foi computada a média aritmética dos valores de Lucro Líquido, Accruals Totais e AD.

Painel D: A partir de cada empresa pertencente ao grupo controle, verificou-se a transição em termos de quintis das $A D$. Identificava-se o ponto em que a empresa estava em determinado ano, e registrava-se em que novo grupo a empresas se enquadrava no ano seguinte.

$$
\text { Teste } \mathrm{t}: * * \text { Sig } 1 \%
$$

nessa faixa, existe número significativo de empresas que "gerenciaram" os resultados para aumentar os lucros.

\section{2 "Gerenciamento" de resultados para sustentar o desempenho}

Segundo Degeorge, Patel e Zeckhauser (1999) uma queda nos resultados, ainda que pequena, é usualmente vista como um ponto negativo, principalmente para aquelas empresas em que existe uma forte perspectiva de crescimento. As empresas de alto valor de mercado em relação ao valor patrimonial são percebidas pelo mercado como capazes de crescer. Neste contexto, acredita-se que, para esse tipo de empresa, existe um incentivo a tentar evitar a queda do resultado e manter o desempenho recente. 
Desse modo, similarmente ao procedimento realizado no item anterior, identificaram-se as empresas com alto valor de mercado em relação ao valor patrimonial no grupo de controle e foram classificadas de acordo com a variação do lucro líquido. Conforme resultados reportados no Painel $B$, o valor das AD médias no intervalo de $0 \%$ a $1,0 \%$ é positivo, ao contrário do resultado no intervalo de $-1,0 \%$ a $0 \%$. Esses números indicam que, em termos médios, as empresas com variação entre $0 \%$ e 1,0\% adotaram práticas no sentido de aumentar os resultados contábeis.

\section{3 "Gerenciamento" de resultados para piorar o resultado}

As empresas que se encontram com resultado contábil muito ruim e que não teriam condições de "manejar" o resultado para melhorá-lo, podem optar por piorá-lo ainda mais, de modo que, no futuro, os resultados venham a ser mais satisfatórios. Na literatura contábil, Healy (1985) denominou esse procedimento como take a bath, afirmando que as empresas procuram reduzir os lucros presentes, mediante o adiamento do reconhecimento de receitas ou acelerando o reconhecimento de despesas.

Para verificar a prática de take a bath pelas empresas brasileiras com resultados muito ruins, classificou-se o total de observações de empresas-ano em cinco subgrupos ordenados decrescentemente de acordo com o valor dos accruals discricionários (AD). No grupo 1, ficam as observações de empresas-ano em que ocorreram os maiores valores positivos de accruals discricionários. Por sua vez, para o grupo 5 restaram as empresas-ano em que ocorreram os maiores valores de accruals discricionários negativos. A partir dessa estratificação, foram computados os accruals discricionários médios e os lucros médios para cada subgrupo, sendo as observações registradas no Painel C da Tabela 2.

Constata-se que, para as empresas que gerenciaram o resultado para baixo de modo mais forte (Quintil 5), encontra-se o pior resultado em termos de rentabilidade. Aquelas empresas que, no geral, estão tendo grandes prejuízos, são justamente as que terão maior propensão a "gerenciar" os resultados para baixo (resultados negativos significativos). Entende-se que essa evidência demonstra bem a prática de take a bath pelas empresas que estão com resultados muito ruins.

\subsection{Reversão dos accruals discricionários}

Quando, por algum motivo, reconhece-se erroneamente os accruals em determinado período, está-se alterando não apenas o resultado corrente, mas também o resultado futuro. A título de exemplo, considere-se o caso das despesas de depreciação. Imagine-se que, deliberadamente, deixa-se de reconhecer as despesas de depreciação. Esse fato terá impacto positivo no período corrente, mas influenciará negativamente no período futuro, quando se tenha que reconhecer cumulativamente as despesas não lançadas nos períodos anteriores. O mesmo fenômeno pode ocorrer em sentido contrário: pode-se reconhecer, no período corrente, despesa de depreciação que só deveria ser lançada no exercício seguinte. Ao fazer isso, carrega-se o período corrente, a favor de resultado mais folgado no exercício futuro.

Desse modo, espera-se que exista sempre uma reversão da posição dos accruals discricionários. Para verificar se essa situação ocorre para os dados estimados, foi estruturada uma matriz de transição dos AD. No Painel D da Tabela 2, procura-se evidenciar a probabilidade de transição de um subgrupo (quintil) para outro. Em termos hipotéticos, a empresa que se encontra em determinado grupo (quintil) passará a outro no período seguinte com que probabilidade (ver notas para detalhes de como a matriz foi elaborada).

A matriz de transição demonstrou que, para a empresa que se situou no quintil 1, há probabilidade de $25,00 \%$ de ficar no mesmo grupo e $24.00 \%$ de se deslocar para o grupo 5 no ano seguinte. Por sua vez, a empresa que estava no quintil 5 tem a probabilidade de $28,00 \%$ de continuar no mesmo quintil e $23,00 \%$ de se transferir para o quintil 1 . A matriz confirmou a idéia de que determinado padrão de gerenciamento não pode ser mantido por muito tempo.

\section{CONCLUSÕES E CONSIDERAÇÕES FINAIS}

A pesquisa desenvolvida oferece pelo menos duas importantes contribuições. Primeiramente, apresenta uma análise crítica dos diversos modelos disponíveis para cálculo dos accruals discricionários, proxy para o gerenciamento dos resultados contábeis. A análise pormenorizada indicou que tecnicamente o modelo de Kang e Sivaramakrishnan (1995) é o que apresenta os melhores resultados e as estatísticas mais robustas. Secundariamente, os resultados do teste do modelo serviram para indicar que as companhias abertas brasileiras gerenciam os seus resultados como resposta a estímulos do mercado.

Entre as evidências do gerenciamento dos resultados contábeis para as empresas brasileiras no período de 1998 a 2004 (Quadro I O).
Apesar dos estudos realizados, não se pode deixar de reconhecer a vulnerabilidade do modelo utilizado para estimar os accruals discricionários. Embora a literatura tenha reconhecido, tecnicamente, o modelo KS como sendo robusto para os seus propósitos, quando se lida com universo de empresas variadas, estimar o comportamento "discricionário" da gestão apenas com procedimentos estatísticos, nunca deve ser a única alternativa, mas serve como instrumento para sinalização.

Este estudo tem importantes implicações para diversos agentes econômicos envolvidos direta ou indiretamente com o mercado de capitais. Os resultados aqui documentados são relevantes para: (a) investidores; (b) autoridades reguladoras; (c) gestores e executivos; (d) empresas de au- 


\begin{tabular}{|c|l|}
\hline Modalidade & $\begin{array}{l}\text { Incentivos para Earnings Management } \\
\text { Dilema: Evita-se reportar pequenos prejuízos. }\end{array}$ \\
$\begin{array}{c}\text { "Gerenciamento" de Resulta- } \\
\text { dos para Evitar Perdas }\end{array}$ & $\begin{array}{l}\text { Evidências: Grande concentração de AD positivas na faixa de pequenos lucros (0\% a 2,5\% dos } \\
\text { ativos totais) }\end{array}$ \\
\hline $\begin{array}{c}\text { "Gerenciamento" de } \\
\text { Resultados para Sustentar o } \\
\text { Desempenho Recente }\end{array}$ & $\begin{array}{l}\text { Dilema: Preocupação em não apresentar queda nos resultados, frustrando expectativas. } \\
\text { Evidências: Empresas com alto MV/BV ratio têm maior propensão ao "gerenciamento" de resul- } \\
\text { tados, com valores positivos de AD em variações de 0\% a 1,0\% dos ativos totais. }\end{array}$ \\
\hline $\begin{array}{c}\text { "Gerenciamento" para piorar } \\
\text { resultados correntes em prol } \\
\text { de resultados futuros }\end{array}$ & $\begin{array}{l}\text { Dilema: "Big Bath" write offs } \\
\text { Evidência: As empresas que, em média, possuíam a maior quantidade de accruals discricionários } \\
\text { negativas, foram as empresas que possuíam, em termos médios, os maiores prejuízos. }\end{array}$ \\
\hline
\end{tabular}

\section{Quadro 1}

ditoria e (e) Escritório de advocacia. Todos esses agentes pautam decisões e atos com base nos relatórios contábeis produzidos pelas companhias.

Para finalizar, é oportuno registrar as inúmeras possibilidades de pesquisa futuras na área de "gerenciamento" dos resultados contábeis (earnings management) no Brasil. Estranhamente, embora esse tema seja palpitante na literatura internacional, poucos estudos foram realizados tentando buscar entender as particularidades específicas brasileiras que poderiam estar motivando as empresas a manejar os seus resultados contábeis. Acredita-se que está aberta uma promissora avenida para futuras pesquisas no Brasil.

\section{Referências}

Burgstahler, D.; Dichev, I. Earnings management to avoid earnings decreases and losses. Journal of Accounting \& Economics, v.24, n.1, p. 99. 1997.

Dechow; P. M.; Sloan, R. G; Sweeny, A. P. Detecting earnings management. The Accounting Review. Sarasota, 70 (2), p. 193-225, 1995.

Degeorge, F.; Patel, J.; Zeckhauser, R. Earnings management to exceed thresholds. Journal of Business, v.72, n.1, janeiro, p. 1-33, 1999.

Healy P. M; Wahlen, J. M. A review of the earnings management literature and its implications for standard setting. Accounting Horizons. Sarasota, 13 p. 365-383, 1999.

Healy, P. M. The effect of bonus schemes of accounting decisions. Journal of Accounting \& Economics. Rochester, 7, p. 85-107, 1985.

Jones, J. J. Earnings management during import relief investigations, Journal of. Accounting Research. Chicago, v. 29, n. 2, p. 193-228, 1991.

Kang, S. H.; Sivaramakrishanan, K. Issues in testing earnings management: an instrumental variable approach. Journal of Accounting Research, Rochester, 33 (2) p. 353-367, 1995.

Kennedy, P. A guide to econometrics. Cambridge: Mit Press, 1998.

Martinez, A. L. 'Gerenciamento' de resultados contábeis: estudo empírico das companhias abertas brasileiras. São Paulo: 2001. Tese (Doutorado em Ciências Contábeis) - Departamento de Contabilidade e Atuária, Universidade de São Paulo, 154 p.

Martinez, A. L.; Cardoso, R. L. Gerenciamento de Resultados Contábeis no Brasil mediante Decisốes Operacionais. In: $30^{\circ}$ Enanpad, 2006 , Salvador.

SCHIPPER, K. Commentary on earnings management. Accounting Horizons. Sarasota, v. 3, p. 91-102, December 1989.

THомаs, J; ZнаNG X. J. Identifying Unexpected Accruals: a comparison of current approaches. Journal of Accounting and Public Policy. New York, $19(4 / 5), 1999$.

\section{NOTA - Endereço dos autores}

Universidade Federal da Bahia

Faculdade de Ciências Contábeis

Praça da Piedade, 06

Salvador - BA

$40070-010$ 